\title{
Correction: Gender-Related Differences in Reliability of Thorax, Lumbar, and Pelvis Kinematics During Gait in Patients With Non-specific Chronic Low Back Pain
}

\author{
Rasool Bagheri, PhD, PT $^{1}$, Ismail Ebrahimi Takamjani, PhD, PT $^{2}$, \\ Mehdi Dadgoo, PhD, PT $^{2}$, Amir Ahmadi, PhD, PT $^{2}$, Javad Sarrafzadeh, PhD, PT $^{2}$, \\ Mohammad Reza Pourahmadi, PhD, PT $^{2}$, Amir-Salar Jafarpisheh, $\mathrm{PhD}, \mathrm{BME}^{3}$ \\ ${ }^{1}$ Neuromuscular Rehabilitation Research Center, Semnan University of Medical Sciences, Semnan; ${ }^{2}$ Department of Physiotherapy, \\ School of Rehabilitation Sciences, Iran University of Medical Sciences, Tehran; \\ ${ }^{3}$ Department of Ergonomics, University of Social Welfare and Rehabilitation Sciences, Tehran, Iran
}

https://doi.org/10.5535/arm.2018.42.2.239

Ann Rehabil Med 2018;42(2):239-249

In this article, the affiliation of the first author should be changed. The revised affiliation information is as below:

${ }^{1}$ Neuromuscular Rehabilitation Research Center, Semnan University of Medical Sciences, Semnan; ${ }^{2}$ Department of Physiotherapy, School of Rehabilitation Sciences, Iran University of Medical Sciences, Tehran; ${ }^{3}$ Department of Ergonomics, University of Social Welfare and Rehabilitation Sciences, Tehran, Iran

This correction has been made to the online version as of Dec 17, 2018.

Corresponding author: Ismail Ebrahimi Takamjani

Department of Physiotherapy, School of Rehabilitation Sciences, Iran University of Medical Sciences, Tehran 15459-13487, Iran. Tel: +98-911129545, Fax: +98-2122228051, E-mail: rasool.bagheri@ymail.com

(c) This is an open-access article distributed under the terms of the Creative Commons Attribution Non-Commercial License (http://creativecommons.org/ licenses/by-nc/4.0) which permits unrestricted noncommercial use, distribution, and reproduction in any medium, provided the original work is properly cited. Copyright $\odot 2018$ by Korean Academy of Rehabilitation Medicine 